\title{
Experiencing In-betweenness
}

\author{
Literary Spatialities
}

\author{
Tahmineh Hooshyar Emami
}

\begin{abstract}
Exploring in-betweenness" is the name of a collection of experiments that originate from my background in Architecture, overlapped with an interest in actual and perceived spaces of refuge. The result is a two-part experiment in which firstly, creative writing and literary analysis were used as vehicles to criticize and suggest alternative hierarchical arrangements of space, and secondly, the experiment which constitutes the topic of this article, where the actual and constructed dialogues between words and buildings are further explored. The author as both an insider and an observer aims to explore the relationship between space, lived experiences and sociological narratives. In "Literary Spatialities," critical spatial writing is used to position the reader as the author through reflective passages and visual reconstructions to explore border encounters between refugee and host communities.
\end{abstract}

KEYWORDS: borders, criticism, hospitality, hostility, jungle, liminality, refugee, space

Nowadays, contemporary urbanization is challenging the notion of permanence as the basic condition of cities. Pop-up temporary settlements, created as a response to disaster or displacement, are assuming new scales and life expectancies. Whether it is because of climate change or political strife, temporary settlements are increasingly expected to last as long as a few generations; thus, there is a necessity to analyze existing typologies and create new breeds or categories of cities that can blur the lines between the temporary and the permanent. For the purpose of this article, I put forward the premise that through the recent mass movement of populations, particularly from the Middle East and North African regions across the European territories, a new type of city has emerged, mostly located at significant border crossings and with a rapid expiration date. Here, I refer to these as "the cities or spaces of in-between." The overarching analysis which I introduce in the following sections aims to investigate unconventional ways in which in-between cities defy the norms of planning and redefine the notion of temporality or historicity.

Governments often concoct temporary solutions to permanent problems. This is the case with refugee camps, which may be subject to a life expectancy of up to 70 years, such as Palestinian camps which have moved away from the notion of temporariness and have become semi-permanent during their 70-year lifetime. In this case, construction materials have changed from ephemeral tarpaulin and canvas to more durable concrete; and public squares and stadiums have taken shape ostensibly to improve the quality of life. These cities present themselves as a microcosm of social layers, political expression, nationalism, religious affairs and geographic and climatic nuances, providing a stage for displacement and integration. This sits in contrast 
with the common dictionary-bound definition of a city as a large town, and/or a relatively large and permanent human settlement. However, reaching a conclusive definition of the notion of cities is far from achievable, particularly in light of the fast-paced changes that urban fabric is subjected to. A closer attempt at interpreting what constitutes a city is Rene Maunier's standpoint, which recognizes the complexity and multi-layered nature of states that a city embodies and hence, defines. Whilst Maunier recognizes the special or multiple characteristics by which a city is defined (i.e. morphological, demographic, administrative, juridical or functional, and alternatively, multiple commonalities of the aforementioned characteristics), he states that a city is a complex local group, or that "in its morphology as in its functioning, it appears to be a community comparable to the rural milieu which surrounds it" (Maunier 1910: 548).

Reverting to the notion of the "in-between city," I have reached the following definition to complement the premise of the research: it is a migratory and transportable entity that moves apace with its inhabitants, existing only briefly in certain transient spatio-temporal conditions. In other words, within the context of refuge, the transportable city will always exist in some form or another, albeit simultaneously tangible and intangible.

With a background in architectural design, overlaid onto research in the field of refugee studies, and a period of writing children's fictional stories, my research into the idea of "inbetweenness" sits at the narrow interdisciplinary intersection of past personal experiences. This has included a cluster of experiments to aid the understanding and design of better city-camps or camp-cities at different scales.

The first highly collaborative experiment developed an analogy between the condition of child refugees en route the European refugee trail to safety and the journey of Alice into Wonderland and Looking-Glass Country as imagined by Lewis Carroll (Hooshyar Emami 2017). Carroll's fictional tale was rewritten from the single-point perspective of Alice, who was now herself a refugee and fleeing from war, traveling across European borders in search of the "Promised Land" and safety, using parallel themes of geographical narratives and journeys (or, in our case, the geopolitical narratives surrounding the pilgrimage through Europe); nonsensical use of language, poetry, and words; laws and regulations; perceptive or static senses of time; and, not the least important, Alice's own character and upbringing in an imperialist society (Bivona 1986: 143).

"Alice's Alternative Wonderland" is the fictitious account of a child's experiences on the European refugee trail and of events as they unfold along her journey. Inspired by Lewis Carroll's Alice in Wonderland and Through the Looking-Glass, which transposes objects and events from the real social and political tableaux of Victorian Britain into a perplexing world of criticism and satire, I made use of critical storytelling in an attempt to understand the logic of the experiences en route, as reflected in the following extract:

All that was left for Alice was the golden key to a home that no longer existed in a war-torn country. She was tired of sitting by the side of the road. She took a bite out of her apple, the taste was sour, much like the taste she felt in her mouth when she thought of home. She had been on the road for a very long time, other travelers had settled along the trail, the world was forgetting the tragedy that had unfolded along these paths. Alice was now looking at resettling and building a new life on the ruins of the one she had left behind. (Notes from Calais field diary, 2015)

The second experiment in the series comes at the point of intersection between words and spaces, or writing and building, which both create or alter already established dialogues between humans and the space occupied by their bodies. The article acts as an experimental test, which we shall name "Experiencing In-betweenness: Literary Spatialities." Although hinted at in the 
Figure 1. Methodology for experimenting literary spatialities.

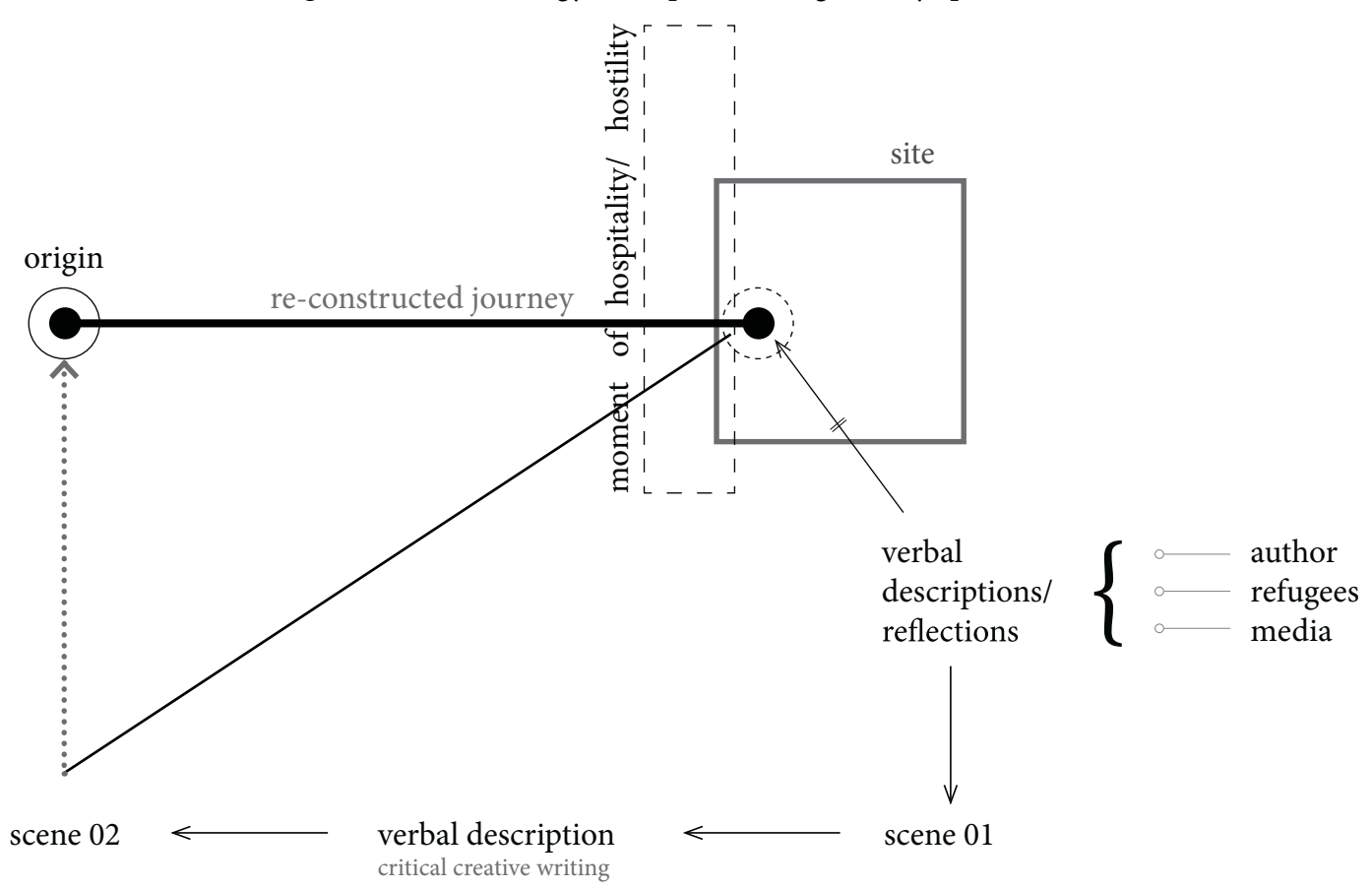

Source: Author, 2017.

first experiment of the research, the second part analyses the loss of the meaning of objects and space and the acquisition of a new meaning in the context of refuge. The first two experiments and the ones to follow are crucial in understanding the power of borders, checkpoints, and their spatial fixity, or lack thereof.

The experiment aims to create a miniature replica of European laws and ever-changing legislation between 2015 and 2016 in the form of direct translations from media representations to formal and geometrical, perceived and conceived spatial practices of hostility, hospitality, deterrence, or incarceration.

Critical creative writing can once again be incorporated in the piece in a similar manner as in the first experiment, in the form of "object or material analysis" or immediate translations of migration trails and host community responses into architectural space.

For the purpose of my research, in the first experiment, I employed the following technique to anonymize and ethicize research relating to refugee studies: the creation and use of a character, named Alice, to relay memories or interactions, and conceal the identities of individuals interviewed during my site visits to refugee camps. Developing from the use of critical creative storytelling in the first experiment, the second experiment employs critical spatial writing as a way of responding to the ever-present need to avoid the use of photography or videography of spaces of migration and refuge, in favor of journal writings and audio transcripts.

Although currently a distant memory for many of those who followed the unraveling of the crisis in 2015 and 2016 through mass media representations, I have crafted a carefully interwoven series of articles, documentaries, journal writings, and photographic accounts collected during that timeframe, which carve out the journey of displaced groups from the heart of their homes in Syria through to Egypt, Turkey, Greece, Macedonia, Slovenia, Serbia, and eventually Northern European countries, as one of the many possible routes to reach Northern Europe. 
The often disjointed or blurred accounts of the journey are reflections on lengthy moments of the voyage where travelers stagnated for months on end, or contrarily, omitted key moments of obscure border crossings, deportations, incarcerations, or even death.

In "Bridge and Door," Georg Simmel (1994: 7) argues that particular architectural forms and man-made constructions are attributed the status of a connector, separator, or delineator of space, and that physical forms can dominate the dynamic and unfolding of daily activities around them. One could conclude that, evidently, space is not only affected by, but also affects relational dialogues between societies and their lived environment through the imposition of new ritualistic experiences of it. Spatial design is indeed a cyclical process whereby spaces are designed to cater for our needs-such as the need for privacy and seclusion, or alternatively the need for connectivity, openness, and comfort, or historically they are used as devices for control and surveillance. Such is the case of commonplace principles of prison design and spatial arrangement which are evident instances where the architecture of control is exerted to impose a certain use or disuse of space.

\section{On Reception and Deterrence}

Hospitality and hostility are, by definition, spatial practices as they assume the crossing of boundaries (Bulley 2015: 5). As discussed by Simmel in "Bridge and Door" (1994: 7), it is human nature to set ourselves boundaries which we can step out of into freedom. Correspondingly, Panu Minkkinen extracts Carl Schmidtt's concept of the unity between localization and order from the land and sea, which theorizes man as a terrain creature bound to the earth in three ways: firstly, in the crop, secondly, in firm boundaries for the distribution and division of land and lastly, through the cycle of harvest (Minkkinen 2007: 57). Focus on the second way in which we are bound to terrain and the concepts of ownership of space and asking for permission to cross certain boundaries into one's home constructs the bones of the ideas discussed in this article.

The "border" is commonly defined as a line separating two countries, administrative divisions, or other areas, and, consequently, has a negotiated geometrical behavior (as lines drawn in cartographic maps), which is then transformed into invisible geopolitical boundaries (not necessarily a physical line drawn on the ground, but rather a negotiated intangible separation), more or less penetrable, and with more or less fixity. Indeed, "the limit, the frontier, the boundary, time-series of boundaries, or ditches, the void, or differance, they are all modifications of the line, the form of topo-logical thinking" (Reichert 1992: 94).

Posing a different interpretation of immeasurable borderlands, Susan Friedman has written of the historical narrative of a Thai epistemology of mapping, which proposed greater fluidity in juxtaposition to the rather rigid and unfamiliar British concepts of an immaterial fixed line separating territories. Speaking of communities in Southeast Asia, Friedman discusses the establishment of temporary borders during times of tension or conflict, which disappeared with the re-negotiation of friendly relations between borderlands. This historical narrative posits borderlands as versatile spatial conditions which, according to the relations between the two territories, expand and contract from spaces of open commerce and cultural exchange to spaces of conflict and confrontation (Friedman 1998: 154). Overlapping the territorial conditions as discussed by Friedman onto current narratives of refuge can be highly relevant in discovering varying gradients or nuances of reception or deterrence at border crossings, from hospitality to soft hostility and violent clashes upon entry (Fiddian-Qasmiyeh and Qasmiyeh 2018). 


\section{A Theatrical Representation}

The site of the experiment is "the Jungle" refugee camp situated at the port of Calais in France, where the complex relationship between the transitory camp and the host-city remained problematic from the moment of its inception to the moment of demolition (one of many demolitions of the camp, in fact) in October 2016. Throughout the existence of the transitory city in this location, established borders between the two neighboring entities often morphed from permeable soft spaces to highly volatile and violent spatial conditions, materialized in the first instance by active police presence and road closures around the perimeter site, to tear gas attacks, violence, and the erection of a three-meter tall fence.

"The Jungle" provided a test-bed for the first experiment of the series and continues to do so for the second experiment as it constitutes the point of convergence between hospitality and hostility, situated between the Port of Calais as the perceived point of hostility and the Port of Dover as the perceived point of hospitality.

Personal writings from the field often capture subjective accounts of the emotional expression of space as inhabited by other individuals. The primary actors that inhabit our surroundings are those who alter our perception of space and its qualities. For instance, the presence of border security guards at the Greek-Macedonian border to perform/enforce the act of selective hospitality (i.e. the admission/acceptance of individuals with particular documentation, journey history, age, gender, or country of provenance) undoubtedly affects the perception of space. Equally, the heavy presence of police vehicles and armed officers around the immediate periphery of "the Jungle" in Calais not only affects and alters the dynamic of individuals in and around that site, it aids in building intangible secure borders between the camp and its host-city, which are inevitably negotiated on a daily basis to allow or deny access to the site.

Figure 2. Scene 101: the western entrance to "the Jungle" refugee camp.

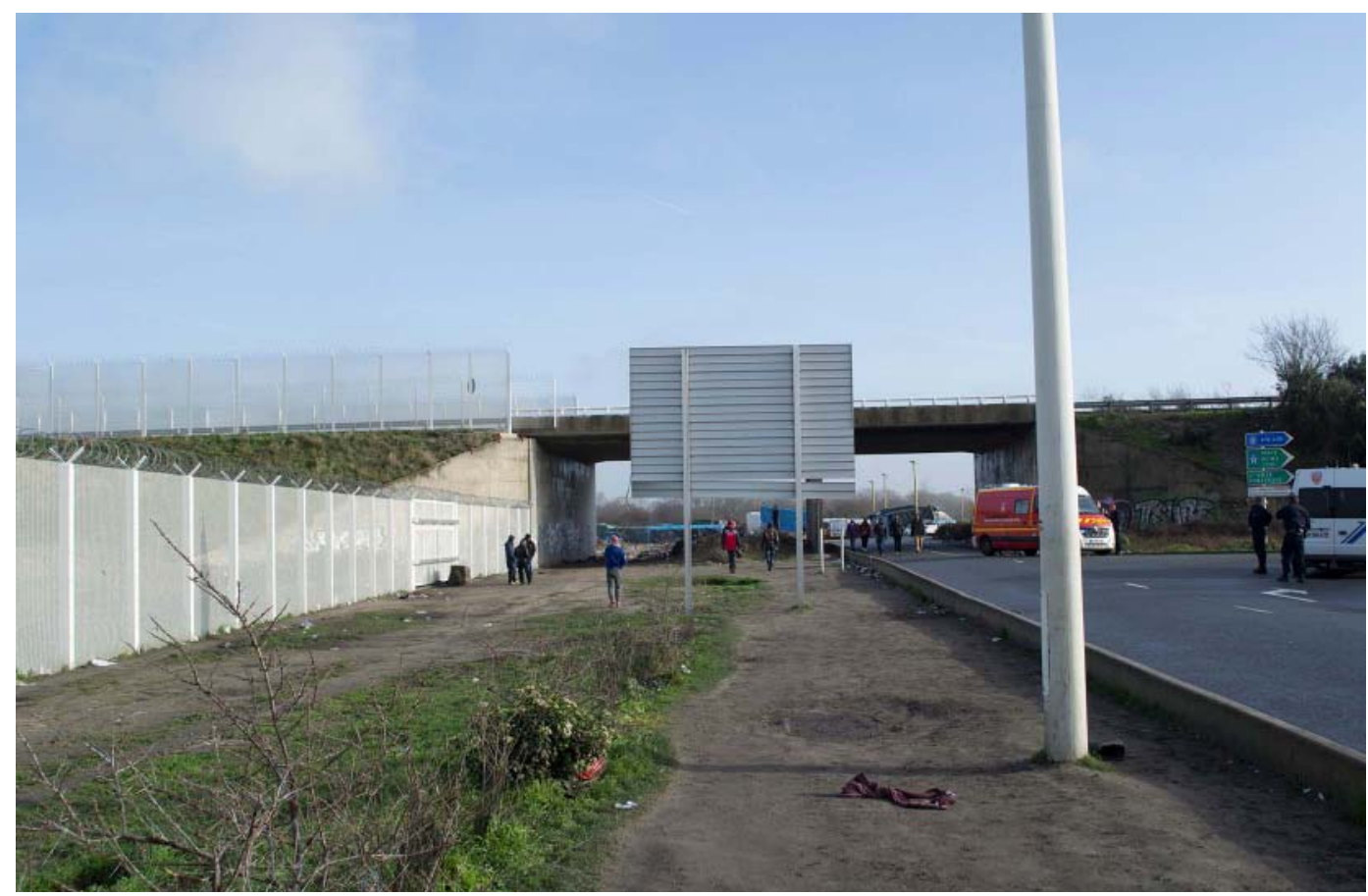

Photograph by the author, 2015. 
Figure 3. Scene 102: first iteration of the space after verbal descriptions are devoid of the source photograph.

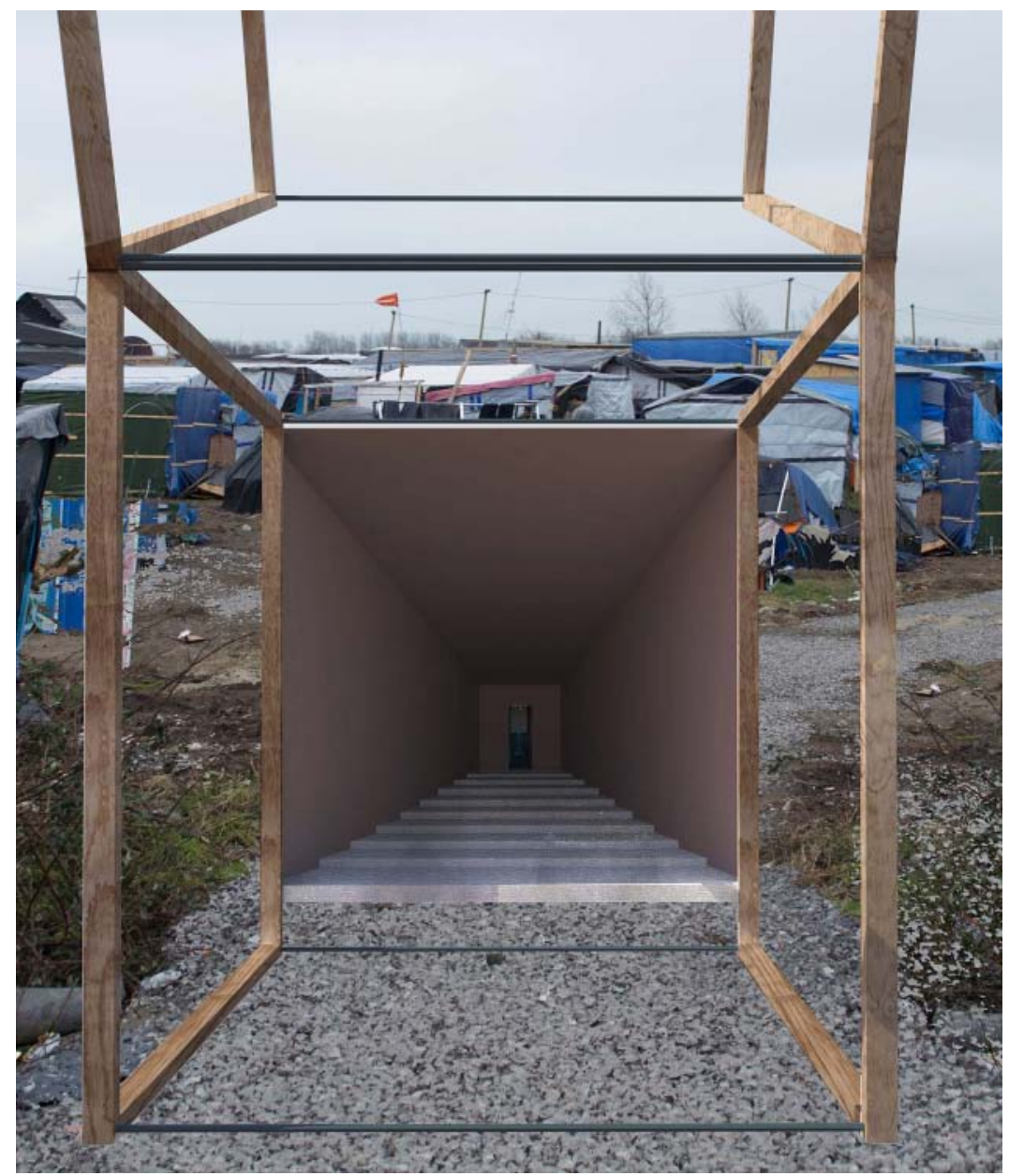

Source: Author, 2015.

I was awoken by the loud banging of a large hand on the windshield. I was struggling to resolve the riddle of the emotional shock from the moment of entry into the Jungle in the protective bubble of our car to the moment of our arrival at the school.

We've stopped. I stare at the ground underneath the car-one step, then the other. The mud is sticky. . . each step is a struggle. Even the ground seems to try to stop you from leaving this place. .. (Notes from Calais field diary, 2015) 
Figure 4. Scene 201: the main high street in the Jungle refugee camp.

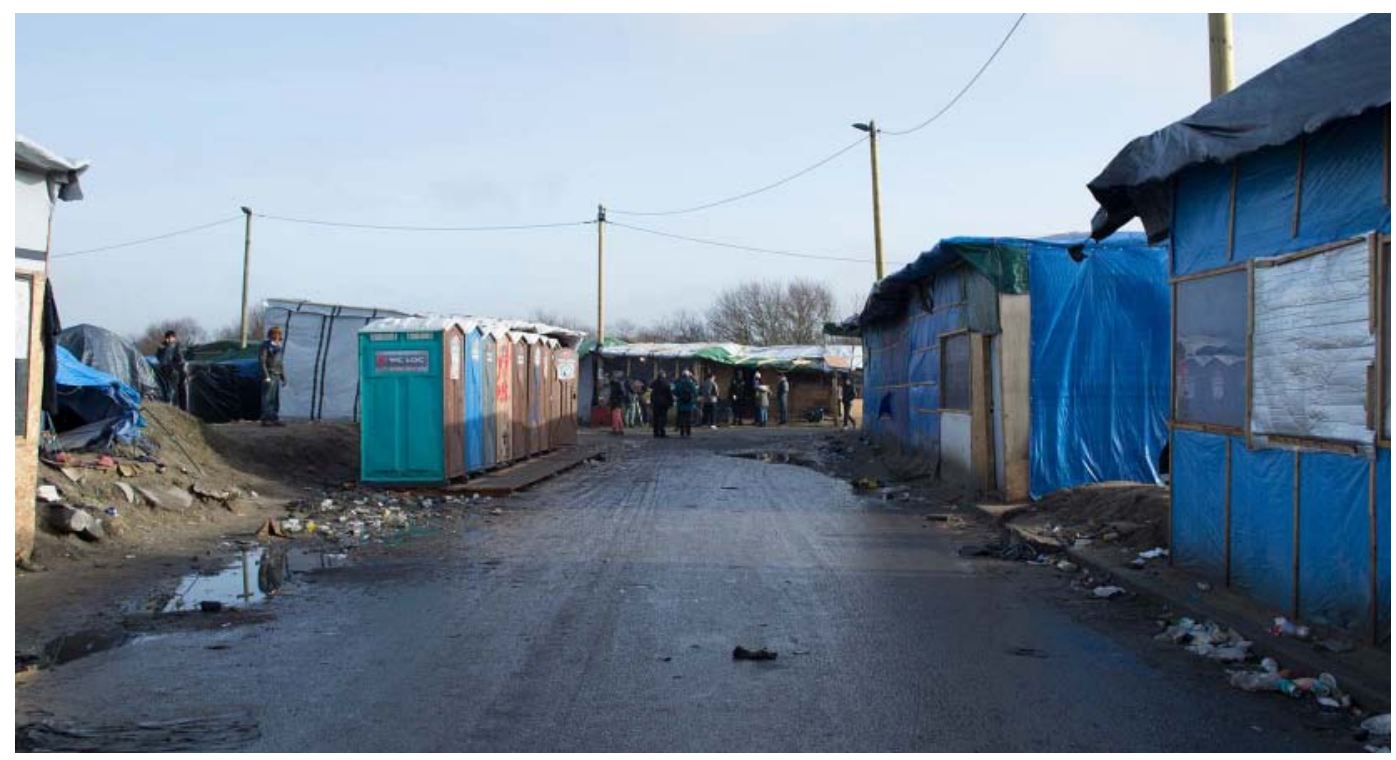

Photograph by the author, 2015 .

Figure 5. Scene 202: first iteration of the space after verbal descriptions are devoid of the source photograph.

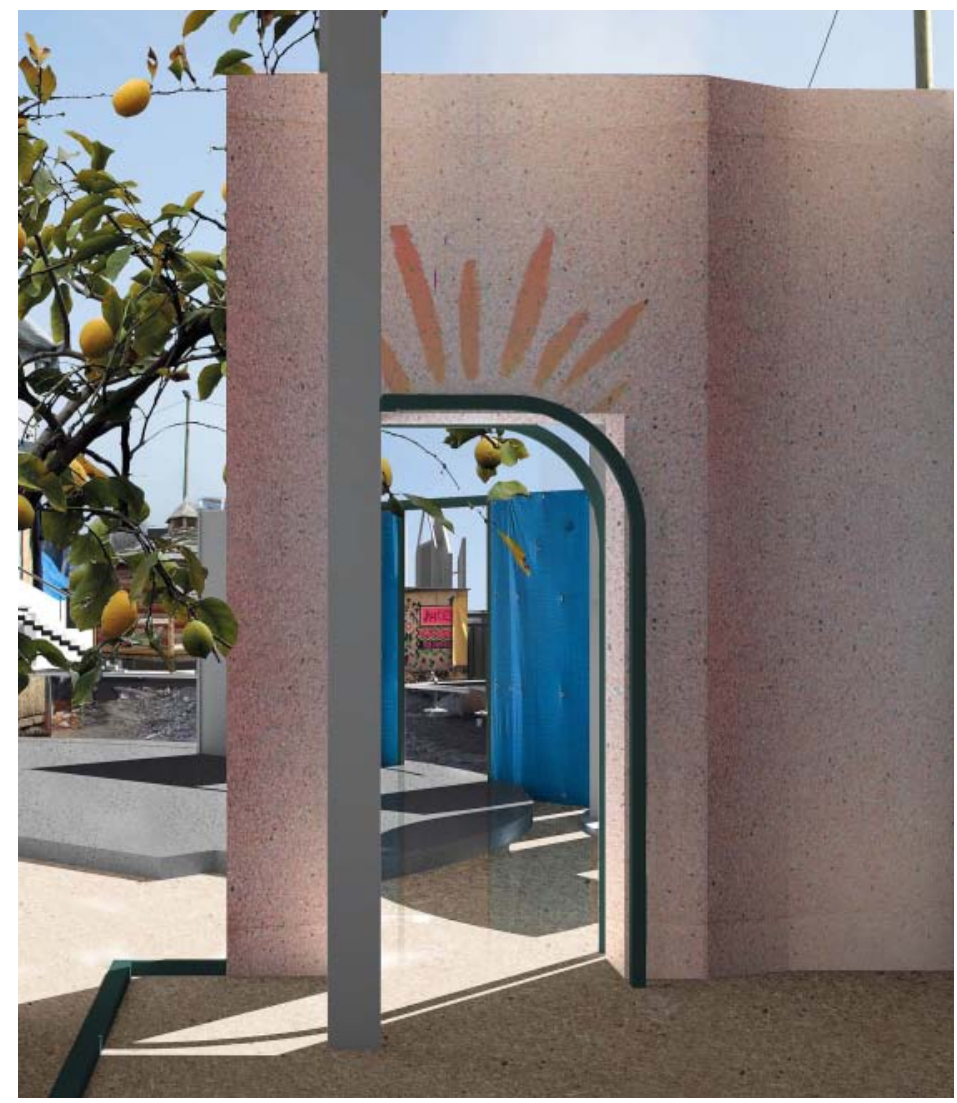

Source: Author, 2015. 
Amidst the blue and white tarpaulin of the make-shift homes built not long ago on top of the industrial waste of wineries and refineries of Calais, a snaky road has carved its way from South to North, spreading its veins through the disorientating pathways to reach the most remote tents and huts.

Scale is redefined in this part of the world. Houses are not as big as we are used to seeing, and not too small to make you feel like Alice trying to fit her unusually large body through the unexpectedly small door. The houses are just a bit taller than their inhabitants, and their inhabitants just a bit shorter, with the only large structure being the slightly skewed top of the Eritrean church rising above the Jungle to peep over to the other side. (Notes from Calais field diary, 2015)

Figure 6. Scene 301: view of the Jungle from above, with the Eritrean church in the background.

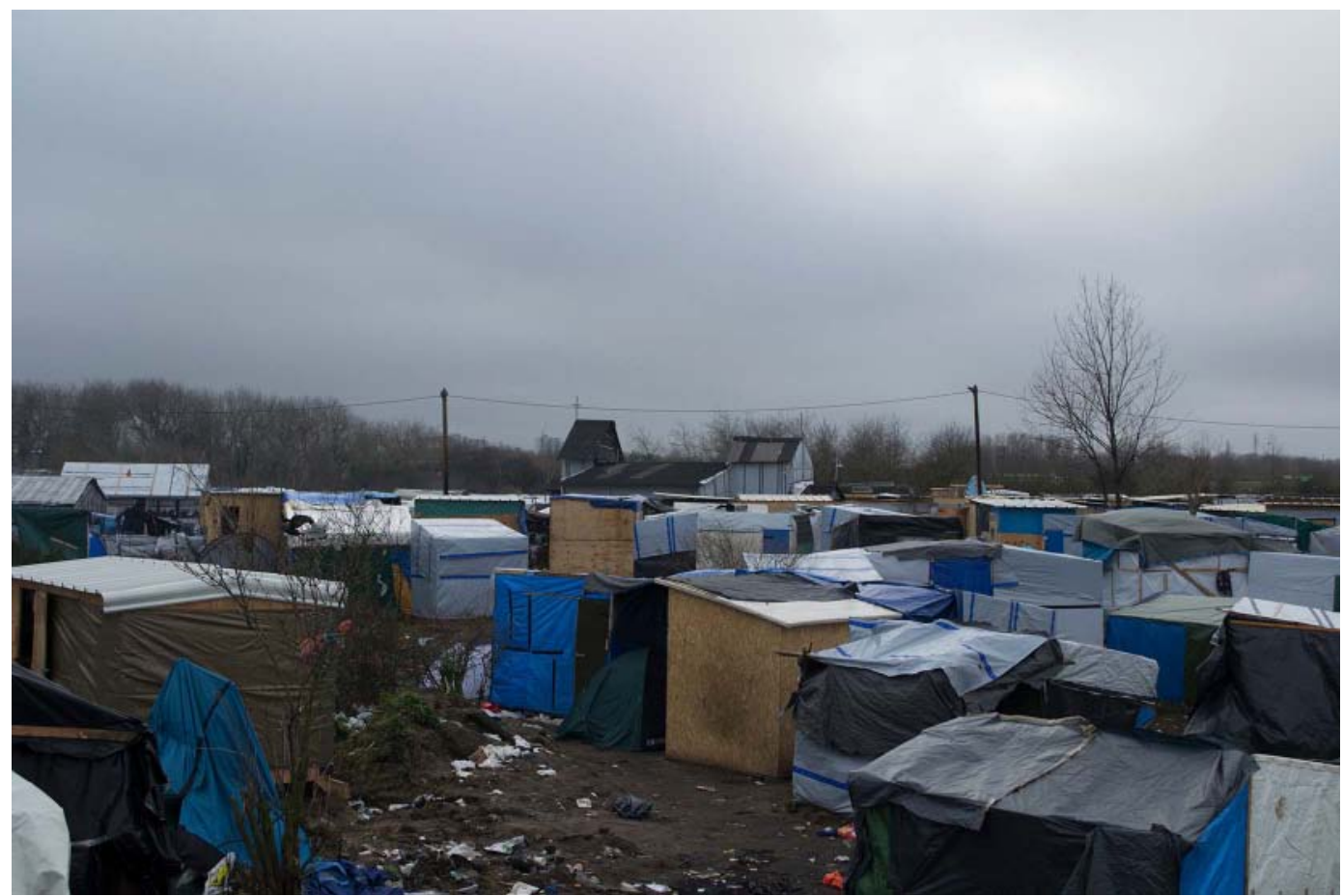

Photograph by the author, 2015. 
Figure 7. Scene 302: first iteration of the space after verbal descriptions are devoid of the source photograph.

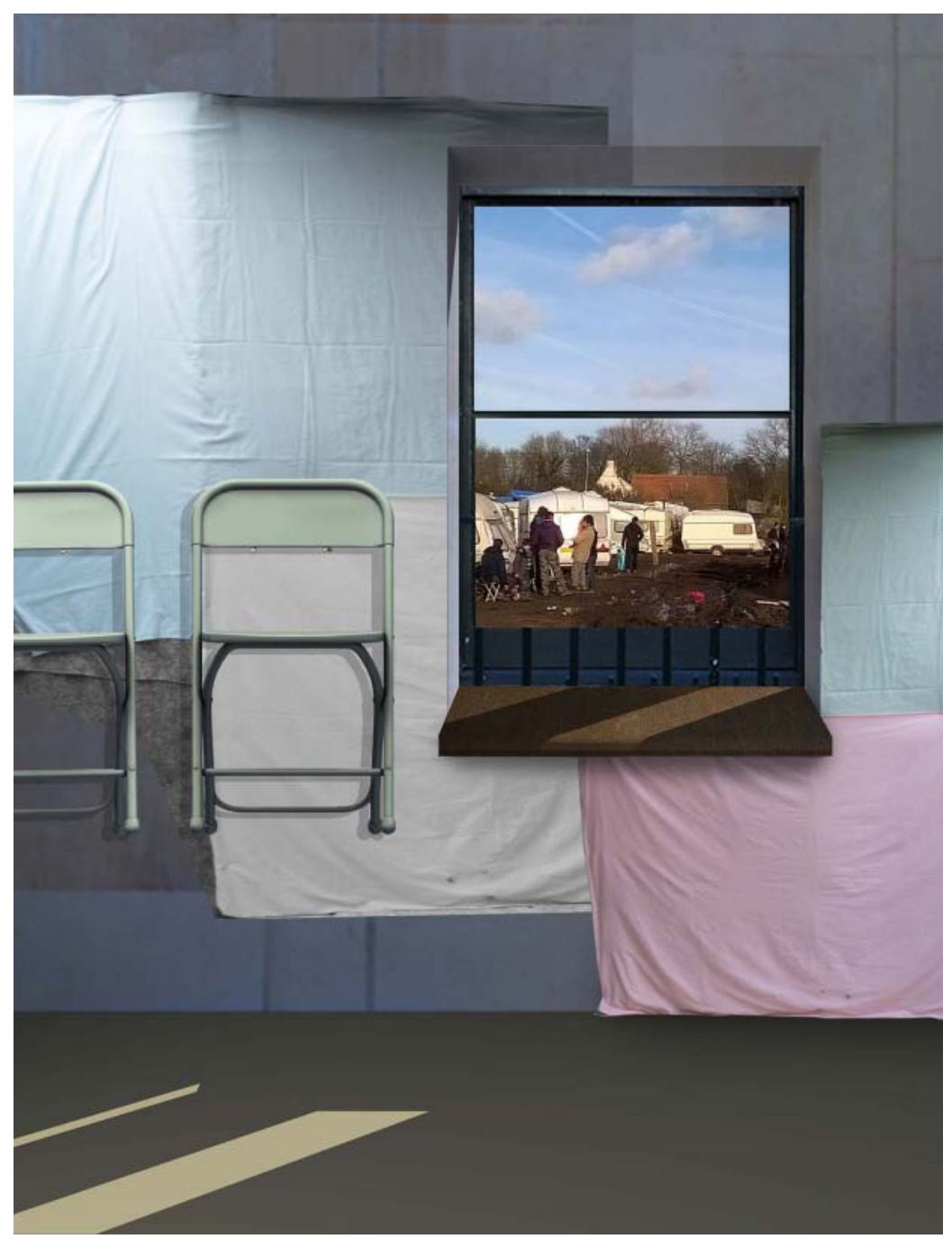

Source: Author, 2015.

Here, I get lost every hour ... All the roads look the same and the tarpaulin covers the real face of the houses. Sometimes, the graffiti you encounter along the pathways guides you to find your destination through the smoke of the barely lit fires.

The house is turned upside down. Much unlike the city where people roam the streets to arrive somewhere, this treeless jungle has, in the spirit of fraternity, inverted this concept: I spend most of the time on the street now together with my brothers in arms. The house is too small, too desolé. Every time a door opens, I secretly hope for a moment where the space inside is larger than it shows from the outside-but of course, this is just another daydream.

Scene 3 is interrupted by his unexpected and sudden invitation to tea.

There is not much to do, except to share stories around a whistling burning kettle on top of a lit fire by the side of the muddy roads. The stone I am sitting on feels uncomfortable, with sharp edges, too close to the ground.

It is always teatime here. (Notes from Calais field diary, 2015) 
TAHMINEH HOOSHYAR EMAMI is an architectural practitioner, activist, design tutor, and writer in the field of humanitarian aid and response. She is a graduate from Newcastle University and the Bartlett School of Architecture at University College London. Tahmineh is an Architecture design tutor at Loughborough University and is currently working in architectural research and practice. In her research, she seeks to investigate the spatial implications of refuge in the context of enforced mobility, using critical creative writing as a tool to explore transitory European refugee camps, focusing on their liminality and transitory geopolitical and demographic position.

\section{REFERENCES}

Bivona, Daniel. 1986. "Alice the Child-Imperialist and the Games of Wonderland", Nineteenth-Century Literature 41 (2): 143. doi: 10.2307/3045136.

Bulley, Dan. 2015. "Ethics, Power and Space: International Hospitality beyond Derrida." Hospitality and Society 5 (2-3): 185-201. doi:10.1386/hosp.5.2-3.185_1.

Carroll, Lewis. 2015. Alice's Adventures in Wonderland \& Through the Looking-Glass. Croydon: Alma Classics.

Fiddian-Qasmiyeh, E., and Y.M. Qasmiyeh. 2018. "Refugee Neighbours and Hostipitality." RefugeeHosts, 20 March. https://refugeehosts.org/2018/03/20/refugee-neighbours-hostipitality/.

Friedman, Susan. 1998. "Routes/Roots: Boundaries, Borderlands, and Geopolitical Narratives of Identity." In Mappings: Feminism and the Cultural Geographies of Encounter, 154 Princeton, NJ: Princeton University Press.

Hooshyar Emami, Tahmineh. 2017. “Reflections on Alice's Alternative Wonderland.” Representations of Displacement, RefugeeHosts, 8 December. https://refugeehosts.org/2017/12/08/reflections-onalices-alternative-wonderland/.

Maunier, Rene. 1910. “The Definition of the City. American Journal of Sociology 15 (4): 536-548.

Minikkinen, Panu. 2007. "Hostility and Hospitality." No Foundations: Journal of Extreme Legal Positivism 4: 53-60.

Reichert, Dagmar. 1992. “On Boundaries.” Environment and Planning D: Society and Space 10 (1): 87-98. doi: $10.1068 / \mathrm{d} 100087$.

Simmel, Georg. 1994. "Bridge and Door." Theory, Culture \& Society 11 (1): 5-10. https://doi.org/10.1177 \%2F026327694011001002. 